\title{
Impact of Online Learning Readiness on Students Satisfaction in Higher Educational Institutions
}

Dr S. Pavan Kumar

Associate Professor \& Head, School of Management,

National Institute of Technology Karnataka (NITK), Surathkal

pavankumar@nitk.ac.in

\begin{abstract}
Recent pandemic has fueled the growth of online learning like never before among the students of all levels. It has opened up tremendous opportunity to evaluate teaching practices through empirical investigation. The purpose of this paper is to examine the relationship between the learners' readiness and their satisfaction towards online education. Online learning readiness is defined as skills needed by students to learn. It emphasises on self-learning management and understanding experiences of selflearning (Smith, 2005). Literature suggests that there are studies that explored the relationship between online learning readiness, academic motivation, perceived learning, cooperative working, achievement and continuation of education (Davis, 2006; Horzum, M. B., Kaymak, Z. D., \& Gungoren, O. C.,2015). However, scholars paid less attention to the relationship between online learning readiness and student satisfaction among undergraduate engineering students. Research by Gunawardena and Duphorne (2000) has identified a direct connection between learning readiness and satisfaction of learning experiences. However, their study was on the adult who had undergone distance study through computer conferencing model. The present study considers a blended online learning model. Data were collected from 155 students who are studying an undergraduate course in Indian universities. The proposed causal relationship was examined with SmartPLS 3, as it is more suitable for the moderate sample size. The research showed a positive relationship between students' online learning readiness and satisfaction. The findings demonstrated a significant relationship between the increasing levels of online learning readiness and student satisfaction. Administrators who are at the helm of responsibility of educational institutions should provide all the required facilities for the teachers to embrace online teaching.
\end{abstract}

Keywords: Online learning readiness, satisfaction, SmartPLS, Higher educational institutions.

\section{Introduction}

Although educational institutions all over the world are witnessing a substantial increase in online learning enrolments from last one decade (Allen \& Seaman, 2017), current Covid-19 situation has left no choice other than learning online for both the educational institutions and the students. As educational institutions are briskly moving towards online platform for delivering their courses, there is a need to identify the factor that can influence students' learning satisfaction. Previous research in the area has recorded many consequences of students' satisfaction with online learning. According to Schreiner and Nelson (2013), students' satisfaction with online learning has an influence on their success. Similarly, student satisfaction with online learning is found to be related to their dropout rates (Ali \& Ahmad, 2011). Students' satisfaction being such an important factor, understanding what affects satisfaction helps the institutions and instructors to improve, include and modify some of the elements of online learning, for example, course design, delivery and evaluation etc. Assessing students' satisfaction allows educational institutions to identify areas for improvement and development of online learning (Kuo, Walker, Schroder, \& Belland, 2014). Hence, present research explored factors such as computer/Internet self-efficacy, self-directed learning, learner control, motivation for learning and online communication self-efficacy that can influence satisfaction with online learning among the students of Indian universities.

\section{Literature Review}

It is not hypothetical anymore to say that online education offers a wide range of facilities to the learners. Many universities all over the world have identified the potential advantages of online education. According to Poole (2000), Chizmar and Walbert (1999) online courses provide learners with a variety of benefits, such as convenience, flexibility etc. However, the important point to address is, are the students ready for online learning?. To probe such question, scholars have conducted many studies to know and understand learner readiness for online learning and its outcomes (Alqurashi, 2019). To better understand how to accomplish effective online learning, we need to have an idea on the dimensions used to measure the readiness as they play a vital role. We have to consider the dimensions that were possibly omitted in previous research. Among the scales available, such as one developed by McVay, (2000, 2001) to measure online readiness, a multidimensional Online Learning Readiness Scale (OLRS) by Hung, Chou, Chen, and Own (2010) that measures college students' readiness for online learning is more comprehensive. It has five dimensions such as self-directed learning, motivation for learning, computer/Internet self-efficacy, learner control and online communication self-efficacy. To the best of scholar's knowledge, till date there exists no study which has used OLRS scale to measure college students' satisfaction. Hence, the present study intends to explore factors that can predict and relate to students' satisfaction with online learning environments in Indian higher education institutions using the scale developed by Hung et 
al. (2010). Assessing student satisfaction permits educational institutions to detect areas for improvement and development of online learning (Kuo et al., 2014).

\section{A. Learner readiness toward online learning (OLRS)}

The readiness levels of students are vital in online education practices. Online learning readiness is one of the important factors that affects learning. Online learning readiness is directly proportional to satisfaction of online learning experiences (Gunawardena \& Duphorne, 2000).

1) Computer and Internet self-efficacy (CIS): We all are aware of the fact that we need proper infrastructure in the form of network, nodes (computers and related devices) and related technology to conduct online course. It would be realistic to assess individuals' ability to make use of such technology to derive its utility. It is basically understanding individuals' computer/network self-efficacy. The idea of self-efficacy is drawn from social cognitive theory, which suggest a theoretical framework for comprehending how self-efficacy beliefs regulate human functioning (Bandura, 1997). Compeau and Higgins (1995) found that computer self-efficacy has a positive influence on computer-use outcomes such as using software to analyse data. Similarly, Tsai and Tsai (2003) found that students with high Internet self-efficacy performed better in web-based task when compared to that of students who had low Internet selfefficacy. Eastin and LaRose (2000) advocated that Internet self-efficacy is one's ability to apply higher-level skills such as troubleshooting technical problems.

2) Online communication self-efficacy (OCS): Communication self-efficacy in online learning is an essential factor for overcoming the problems related to online communication (Hung et al., 2010). Online education essentially involves computer-mediated communication. To be successful, a student should engage actively in online discussions with fellow students, ask questions to teachers to understand the subject in-depth, and work with other online students etc. Roper (2007) recommended that successful students should make use of online discussions. It is essential to create chances for interactions and communications between students and their teachers' in online learning environment (McVay, 2000).

3) Self-directed learning (SDL): One of the important characteristics of online learning is its flexibility. Learner need not be tied up with a strict timeline in the process of learning the online content. Previously research has found that to be successful, online learners should make selfdecisions to suit their learning style and capability (Lin \& Hsieh, 2001). Online learners should adopt suitable learning strategies to establish learning goals and also to evaluate learning outcomes. There exists relationship between online learners taking their own decisions and their enthusiastic participation in online learning activities (Hung et al., 2010).

4) Motivation for learning (MFL): Motivation has an important part in student achievement (Eccless \& Wigfield, 2002). The theoretical framework which explains the process of motivation is goal-oriented behaviours (Maehr \& Meyer, 1997). Academic motivation is defined as enthusiasm a student demonstrates during learning activities, and the magnitude of attention a student puts into different learning activities (Cave, 2003). It is closely related to the self-efficacy beliefs that students have on themselves (Zimmerman, 2000). Students' who are motivationally oriented are expected to demonstrate significant effects on their learning performance (Hung et al., 2010). Saadé, He and Kira (2007) found that motivation has vital role in the success or failure of online learning.

5) Learner control ( $L C)$ : In an online learning environment, students have complete control on what to learn next and what to skip. He/she can comfortably streamline the learning activity based on their comfort and convenience. One can decide on how much to learn at a given time and learners have control over their own instruction. They can adopt individualised approach by repeating or skipping sections. Learner control is the degree to which an online learner can decide his/her own learning process (Shyu \& Brown, 1992). Online learners who are better empowered to determine their own learning may exhibit better learning performance (Hung et al., 2010). According to Merrill (1984), learner should be given free-hand over the order of instructional material he/she makes use.

\section{B. Satisfaction (SS)}

Going forward, universities offering courses through online mode is going to grow bigger and bigger. Hence research is needed to know about the students' experiences, specifically about their satisfaction with online learning (Halter, Kleiner, \& Hess, 2006). In addition to that, identifying the factors that can influence student satisfaction should be on the priority list. Student satisfaction tells us how learners view their overall online learning experience. Student satisfaction with online learning is well recognised in the previous researches. Student satisfaction was significantly related to students' success rates, and commitment to complete an online course etc. (Ali \& Ahmad, 2011; Yukselturk \& Yildirim, 2008). Assessing student satisfaction allows people who are at the helm of university administration to identify areas for improvement and development of online learning (Kuo et al., 2014). Self-efficacy is considered an important factor in predicting student satisfaction (Alqurashi, 2019). However, there exists a lot of contradictory findings regarding the relationship between students' internet/computer selfefficacy and their satisfaction with online learning. For example, a study by Lim (2001) found that computer selfefficacy was a significant predictor of student satisfaction. Such results are also supported with the research by Womble (2007), which showed that computer self-efficacy has a significant positive relationship with student satisfaction. Similarly, there exists a few studies which say no relationship exists between the two variables. For example, a few recent studies (Simmering, Posey, \& Piccoli, 2009; Wu, Tennyson, \& Hsia, 2010; Jan, 2015) found that computer self-efficacy does not significantly affect student satisfaction. It is evident from the literature that there exists an ambiguity on the relationship between 
efficacy and satisfaction relationship. One of the important reasons for such an ambiguity could be attributed to the dimensionality of efficacy construct. More research is warranted in the areas where ambiguity exists. In addition, there is limited research on the relationship between selfefficacy and student satisfaction (Alqurashi, 2019). Hence, the present study uses more comprehensive online learning readiness scale to understand its relationship with student's satisfaction with online learning.

\section{Objectives of the Study}

To the best of researcher's knowledge, there exists no study that used computer/Internet self-efficacy (CIS), Online communication self-efficacy (OCS), Self-directed learning (SDL), Motivation for learning (ML) and Learner control (LC) in multiple predictive models to examine whether they predict satisfaction with online learning. The findings of this study could help people involved in online education to plan, design, and deliver online content more effectively. Therefore, the present study examines the following research questions:

Research question 1: To what extent the five dimensions of OLRS scale (CIS, OCS, SDL, ML, and LC) will independently predict student satisfaction with online learning?

Research question 2: To identify the strongest predictor of student satisfaction with online learning among the most significant predictor/(s) of OLRS?

Research question 3: To what extent all the five dimensions of OLRS put together can predict student satisfaction with online learning?

\section{Method}

In the current study, a research model was developed based on the literature review and the gap area to investigate the relationship between online learning readiness construct and students' satisfaction with the online learning. The sample for the study were drawn from the students studying different programs in Indian universities. 155 students have come forward to fill the survey instrument using the convenience sampling method and they constitute the research sample for the study. As it was convenient to reach the students via internet and google forms during this pandemic period, convenience sampling method was preferred. All the participants have either undergoing or completed at least one online course. Among the respondents, 54.8 percentage were male students and 45.2 respondents were female students. The average age of the respondents was 21 years.

To measure student levels of online learning readiness, an Online Learning Readiness Scale (OLRS) was used. It has five dimensions with a total of 18 items. This is a 5-point Likert-type scale was developed by Hung et al. (2010). The 5 factors are computer/internet self-efficacy with 3 items, self-directed learning with 5 items, learner control with 3 items, learning motivation with 4 items, and online communication self-efficacy with 3 items. The satisfaction scale used in the study was developed by Gunawardena and Zittle (1997) and originally consists of ten items. However, the present study used nine items only, one item was not relevant to the current study and hence it was not considered. The anchors were on a 5-point Likert scale with a score of $1=$ strongly disagree, $2=$ disagree, $3=$ uncertain, 4 agree, and $5=$ strongly agree.

\section{Results}

Table 1: Showing descriptive statistics

\begin{tabular}{lccccc}
\hline Scales & Items & Mean & SD & $\begin{array}{c}\text { Mean Inter- } \\
\text { item }\end{array}$ & $\begin{array}{c}\text { Composite } \\
\text { Reliability } \\
\text { correlation }\end{array}$ \\
\hline CIS & 3 & 3.06 & .991 & .375 & .799 \\
OCS & 3 & 2.87 & 1.05 & .439 & .826 \\
SDL & 5 & 2.83 & .805 & .229 & .752 \\
ML & 4 & 2.92 & .967 & .352 & .806 \\
LC & 3 & 2.53 & .874 & .298 & .768 \\
SS & 9 & 2.55 & .793 & .397 & .886
\end{tabular}

Note: computer/Internet self-efficacy (CIS), Online communication selfefficacy (OCS), Self-directed learning (SDL), Motivation for learning (ML), and Learner control (LC).

The Cronbach's alpha values are sensitive to number of items in the scale. Hence, when number of items in a scale are fewer than 10 items, Cronbach's alpha values can be quite small. In such a situation, it is recommended to report the mean inter-item correlation for the items (Pallant, 2020). According to Briggs and Cheek (1986), the optimal mean inter-item correlation values range from .2 to .4. Similarly, Clark and Watson (1995) recommend mean inter-item correlations between .15 and .50. See table 1, mean Interitem correlation of the five dimensions were within the limits of the recommended range. In addition, adequate composite reliability values were also reported.

Table 2: Showing correlations, Average variance extracted and square root of Average variance extracted

\begin{tabular}{ccccccc}
\hline & CIS & SDL & LC & ML & OCS & SS \\
\hline CIS & $\begin{array}{c}0.57 \\
(.75)\end{array}$ & & & & & \\
SDL & 0.52 & $\begin{array}{c}0.4 \\
(.63)\end{array}$ & & & & \\
LC & 0.47 & 0.66 & $\begin{array}{l}0.53 \\
(.72)\end{array}$ & & & \\
MFL & 0.49 & 0.55 & 0.52 & 0.51 & & \\
OCS & 0.55 & 0.55 & 0.52 & 0.61 & 0.61 & \\
SS & 0.44 & 0.52 & 0.54 & 0.40 & 0.51 & 0.5 \\
\hline \hline
\end{tabular}

Note: Computer/Internet Self-efficacy (CIS), Online Communication Selfefficacy (OCS), Self-directed learning (SDL), Motivation for learning (ML), and Learner control (LC). All correlations are significant at the 0.01 level (2-tailed). Average Variance Extracted (AVE) values are shown in italics, whereas square root of AVEs are shown in parenthesis.

Research question 1: To what extent the five dimensions of OLRS scale (CIS, OCS, SDL, ML, and LC) would independently predict student satisfaction with online learning? 


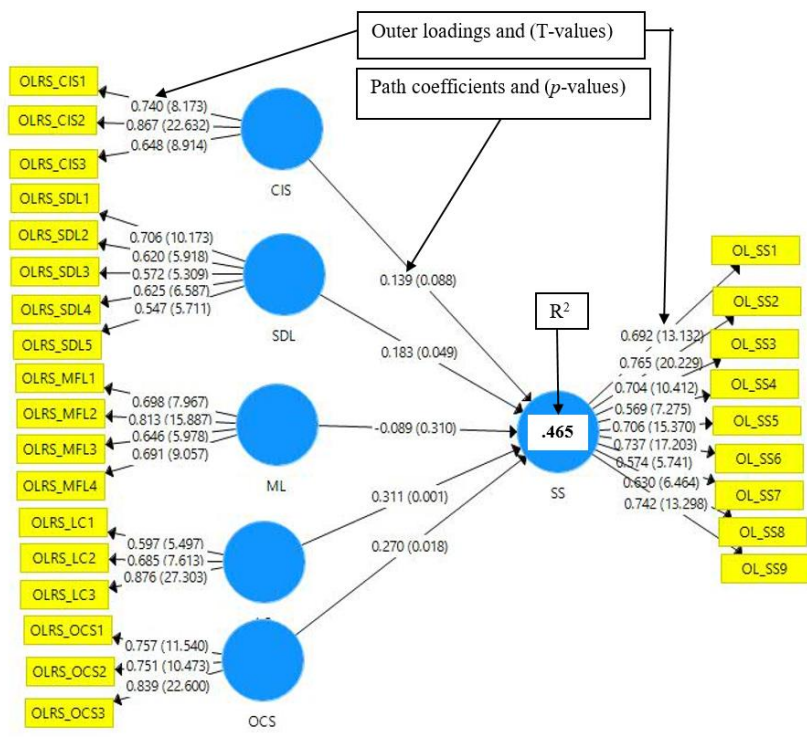

Figure 1: Computer/Internet self-efficacy (CIS), Online communication self-efficacy (OCS), Self-directed learning (SDL), Motivation for learning (ML), and Learner control (LC). All five dimensions of OLRS individually predicting students' satisfaction (SS) with online learning.

We have already seen that the study variables have shown adequate composite reliability and mean inter-item correlations. Moving ahead, validity of the study constructs should be ensured. Usually, the two important forms of validity that are reported in research papers are convergent validity and discriminant validity. One of the methods to verify convergent validity is with the help of AVE values. According to Hair et al., (1998), it should greater than .5. In the present study, OLRS scale dimensions and satisfaction construct have either greater than .5 or close to .5 AVE (see table 2). Similarly, to determine if there is discriminant validity, square roots of AVEs should be greater than the correlations between constructs. For the present research, the square root of AVE values was ranging from .63 to .78 and they were greater than the correlations between the constructs. Hence, both convergent validity and discriminant validity is achieved (see table 2). Multicollinearity values were also verified. It is important to check for multi-collinearity issues, as it can seriously bias the results. Methodological research advocates that Variance Inflation Factor (VIF) should be either 3.3 or less to avoid any issues related to multi-collinearity (Kock \& Lynn, 2012). The VIF values for the current study were well within the range i.e., from $1.06-2.30$.

Figure 1 shows outer or factor loadings, $\beta$ path coefficients, and $\mathrm{R}^{2}$ values. All the item loadings on their respective constructs were measured above .50. and all were significant at $p<.001$. T-values were shown in parenthesis for all the indicator variables. Any value for T-statistic above 1.96 is considered as having significant level (Hair, Hult, Ringle \& Sarstedt, 2016). $\beta$ path coefficient between computer/Internet self-efficacy, Motivation for learning and student satisfaction with online learning environments is non-significant at $p<.05$ (see figure 1). Similarly, $\beta$ path coefficient between Self-directed learning (SDL), Learner control (LC), Online communication self-efficacy (OCS) and students' satisfaction with online learning environments is significant at $p<.05$ (see figure 1 ) with $\beta$ values of $.183, .311$, and .270 respectively. To summarise, among the five dimensions of OLRS scale, only three dimensions such as SDL, LC, and OCS could significantly predict students' satisfaction with online learning environment.

Research question 2: To identify the strongest predictor of student satisfaction with online learning among the most significant predictor/(s) of OLRS?

Among the three predictors (SDL, LC, and OCS), $\beta$ path coefficient between Learner control (LC) and students' satisfaction with online learning environments is stronger with $\beta=.311, p=.001$. Whereas, $\beta$ path coefficient between Self-directed learning (SDL), Online communication selfefficacy (OCS) and students' satisfaction with online learning environments is $\beta=.183, p<.05 ; \beta=.270, p<.05$ respectively.

Research question 3: To what extent all the five dimensions of OLRS put together can predict student satisfaction with online learning?

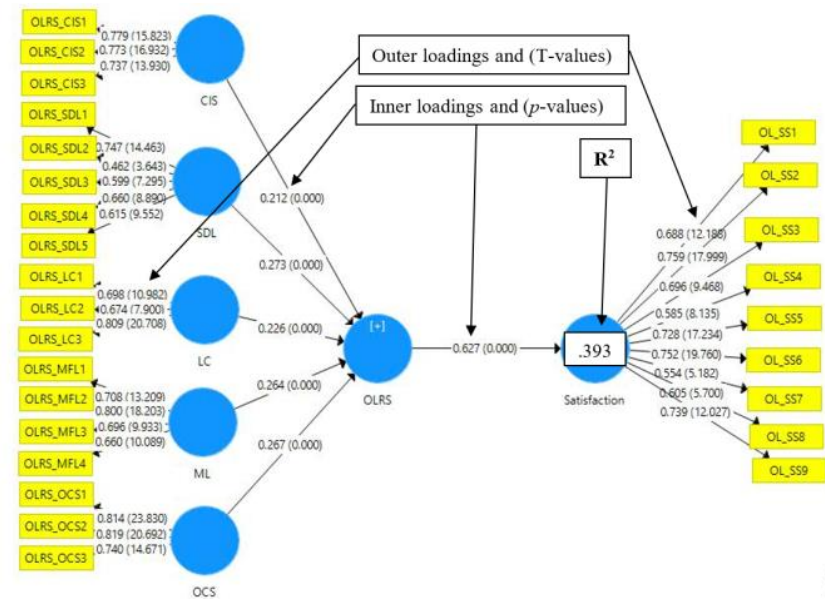

Figure 2: Second order OLRS construct. (All five dimensions of OLRS scale such as Computer/Internet self-efficacy (CIS), Online communication self-efficacy (OCS), Self-directed learning (SDL), Motivation for learning (ML), and Learner control (LC) loading on to OLRS construct) are together predicting student satisfaction within online learning.

Figure 2 shows outer or factor loadings, $\beta$ path coefficients, and $\mathrm{R}^{2}$ values. All the item loadings on their respective constructs were measured either above or close to .50 . and all were significant at $p<.001$. T-values are shown in parenthesis for all the indicator variables. $\beta$ path coefficient between OLRS and student satisfaction with online learning environments is significant at $p<.001$ with a $\beta$ value of .627 (see figure 2). To summarise, OLRS as a construct is a strong predictor of students' satisfaction with online learning environment vis-à-vis when compared to each dimension of OLRS predicting students' satisfaction. However, the overall model quality can be assessed based on the ability of its exogenous constructs predicting the endogenous constructs. Coefficient of determination $\left(\mathrm{R}^{2}\right)$ is a measure of the model's predictive accuracy.

For the present model as shown in figure 1 and figure 2, the coefficient of determination $\mathrm{R}^{2}$ values are .465 and .393 
respectively. In both the cases, the exogenous constructs of the model have achieved moderate prediction accuracy.

For the model presented in figure 1, where all the dimensions of OLRS independently predicting students' satisfaction has $\mathrm{R}^{2}$ value of .465 . It means that the dimensions of the exogenous construct, i.e., OLRS can explain 46.5 percentage of variance in students' satisfaction with online learning. Similarly, when considering OLRS as a construct predicting endogenous construct students' satisfaction, $\mathrm{R}^{2}$ value of the model is .393 , which essentially means that OLRS as a second-order construct could only explain 39.3 percentage of variance in students' satisfaction with online learning. Looking at the overall model quality, model shown in figure 1 has better predictability.

\section{Discussion and conclusion}

The current study has made unique contributions to the existing knowledge base. Till date, there is no study that has made a comprehensive enquiry on the predictors of students' satisfaction with online learning among the students of Indian universities. It is much needed as every university of the globe is forced to embrace the online teaching and learning, especially due to the prevailing Covid-19 situation. Primarily the study was designed to identify the predictors of students' satisfaction with online learning. This is because satisfaction was highlighted as one of the important factors that determine the quality of online instruction (Moore \& Kearsley, 2012). This research attempted to understand the relationship between five dimensions of OLRS construct (CIS, SDL, LC, ML, and OCS) and student satisfaction with online learning. Two different models were tested. The first one being five dimensions of OLRS scale predicting students' satisfaction independently and the second one being collectively as a single construct (see figure 1 and 2). It is evident for the results that the former model's predictability was higher when compared to the later model. Both the models have exhibited sufficient psychometric properties and hence they were validated. The results showed that self-directed learning (SDL), Learner control (LC), Online communication self-efficacy (OCS) were critical factors in predicting student satisfaction. This study augments that Learner control (LC) is the strongest predictor and the most important contributor to students' satisfaction with online learning. Results suggest that it is more likely to have high students' satisfaction if students come to an online course with some preparation to give direction to his/her own learning progress. The sample chosen for the study are young adults and many of them are on multiple social media platforms simultaneously. Hence, it is quite likely that they pay divided attention between their online learning process and their engagement on social media platforms. Administrators should pay at most attention while designing and deploying online learning content. Online content should be designed in such a way that they engage students to a maximum extent, thereby stopping them form getting diverted to social media platforms. The results even suggest that the content delivery should be according to the students' need basis, but not on one size fits all concept. Online communication self-efficacy was identified as predictor of satisfaction. The one who is confident of using online tools to communicate effectively through text, discussion forums etc. are the one among the satisfied students. The findings of this research stresses the importance of self-efficacy for learning online. Results are consistent with previous studies such as Gunawardena, Linder-VanBerschot, LaPointe, and Rao (2010), Shen, Cho, Tsai, and Marra (2013) and Alqurashi (2019) etc. who found self-efficacy for learning is related to student satisfaction. Self-directed learning (SDL) is not so strong predictor of student satisfaction. However, results demonstrated that the one who is inclined towards selfdiscipline in managing their time well, setting up their learning goals, consulting people to solve learning problems, and keen on their performance are the one who are satisfied with online learning environments. Further research could examine different factors that might improve the learner outcomes.

\section{Limitations}

As the data used for the study is cross-sectional, the findings of this research paper should be generalised with caution.

\section{Acknowledgement}

I sincerely express my gratitude to Dr Vikram Kulkarni, Dr P Sambaji Rao and other colleagues working for various Indian universities for helping me in data collection process. I also thank my research scholar Mr Ansab K V for his support.

\section{References}

Ali, A., \& Ahmad, I. (2011). Key Factors for Determining Student Satisfaction in Distance Learning Courses: A Study of Allama Iqbal Open University. Contemporary Educational Technology, 2(2), 118-134. https://doi.org/10.30935/cedtech/6047

Allen, I. E., \& Seaman, J. (2017). Digital Compass Learning: Distance Education Enrollment Report 2017. Babson survey research group.

Alqurashi, E. (2019). Predicting student satisfaction and perceived learning within online learning environments. Distance Education, 40(1), 133-148.

Bandura, A. (1997). Self-efficacy: The exercise of control. New York: W.H. Freeman.

Briggs, S. R., \& Cheek, J. M. (1986). The role of factor analysis in the development and evaluation of personality scales. Journal of personality, 54(1), 106-148.

Cave, S. L. R. (2003). The effects of strengths education on the academic motivation of first-year college students (Doctoral dissertation, Azusa Pacific University, California). Available from ProQuest Dissertations and Theses database. (UMI No. 3082036)

Chizmar, J. F., \& Walbert, M. S. (1999). Web-based learning environments guided by principles of good teaching practice. Journal of Economic Education, 30(3), 248-264.

Clark, L. A., \& Watson, D. (1995). Constructing validity: Basic issues in objective scale development. Psychological Assessment, 7(3), 309-319. https://doi.org/10.1037/10403590.7.3.309 
Compeau, D. R., \& Higgins, C. A. (1995). Computer selfefficacy: development of a measure and initial test. MIS Quarterly, 19(2), 189-211.

Davis, T. S. B. (2006). Assessing online readiness: Perceptions of distance learning stakeholders in three Oklahoma community colleges (Doctoral dissertation, Oklahoma State University).

Eastin, M. S., \& LaRose, R. (2000). Internet Self-Efficacy and the Psychology of the Digital Divide. Journal of Computer-Mediated Communication, 6(1). https://doi.org/10.1111/j.1083-6101.2000.tb00110.x

Eccless, J. S., \& Wigfield, A. (2002). Motivational beliefs, values and goals. Annual Review of Psychology, 53, 109132.

Gunawardena, C. N., \& Zittle, F. J. (1997). Social presence as a predictor of satisfaction within a computer-mediated conferencing environment. American journal of distance education, 11(3), 8-26.

Gunawardena, C. N., \& Duphorne, P. L. (2000). Predictors of learner satisfaction in an academic computer conference. Distance Education, 21(1), 101-117. https://doi.org/10.1080/0158791000210107

Gunawardena, C. N., Linder-VanBerschot, J. A., LaPointe, D. K., \& Rao, L. (2010). Predictors of Learner Satisfaction and Transfer of Learning in a Corporate Online Education Program. American Journal of Distance Education, 24(4), 207-226. https://doi.org/10.1080/08923647.2010.522919

Hair, J. F., Black, W. C., Babin, B. J., Anderson, R. E., \& Tatham, R. L. (1998). Multivariate data analysis (Vol. 5, No. 3, pp. 207-219). Upper Saddle River, NJ: Prentice Hall. Hair Jr, J. F., Hult, G. T. M., Ringle, C., \& Sarstedt, M. (2016). A primer on partial least squares structural equation modeling (PLS-SEM). Sage publications.

Halter, M. J., Kleiner, C., \& Hess, R. (2006). The experience of nursing students in an online doctoral program in nursing: A phenomenological study. International Journal of Nursing Studies, 43, 99-105.

Horzum, M. B., Kaymak, Z. D., \& Gungoren, O. C. (2015). Structural equation modeling towards online learning readiness, academic motivations, and perceived learning. Educational Sciences: Theory \& Practice, 15(3).

Hung, M.-L., Chou, C., Chen, C.-H., \& Own, Z.-Y. (2010). Learner readiness for online learning: Scale development and student perceptions. Computers \& Education, 55(3), $1080-1090$.

Jan, S. K. (2015). The relationships between academic selfefficacy, computer self-efficacy, prior experience, and satisfaction with online learning. American Journal of Distance Education, 29(1), 30-40.

Kock, N., \& Lynn, G. (2012). Lateral Collinearity and Misleading Results in Variance-Based SEM: An Illustration and Recommendations. Journal of the Association for Information Systems, 13(7), 546-580.

Kuo, Y.-C., Walker, A. E., Schroder, K. E. E., \& Belland, B. R. (2014). Interaction, Internet self-efficacy, and selfregulated learning as predictors of student satisfaction in online education courses. The Internet and Higher Education, 20, 35-50.

Lim, C. K. (2001). Computer self-efficacy, academic selfconcept, and other predictors of satisfaction and future participation of adult distance learners. American Journal of Distance Education, 15(2), 41-51.

Lin, B., \& Hsieh, C. T. (2001). Web-based teaching and learner control: a research review. Computers \& Education, 37(4), 377-386.

Maehr, M., \& Meyer, H. (1997). Understanding motivation and schooling: Where we've been, where we are, and where we need to go. Educational Psychology Review, 9, 371-409. McVay, M. (2000). Developing a web-based distance student orientation to enhance student success in an online bachelor's degree completion program. Unpublished practicum report presented to the Ed.D. Program. Florida: Nova Southeastern University.

McVay, M. (2001). How to be a successful distance learning student: Learning on the Internet. New York: Prentice Hall.

Merrill, M. D. (1984). What is learner control? In R. K. Bass, \& C. D. Dills (Eds.), Instructional development: The state of the art II (pp.221-242) Dubuque, IA: Kendall Hunt Pub Co

Moore, M. G., \& Kearsley, I. G. (2012). Distance education: A systems view of online learning (3rd ed.). New York, NY: Wadsworth Publishing Company.

Pallant, J. (2020). SPSS survival manual: A step by step guide to data analysis using IBM SPSS. Routledge.

Poole, D. M. (2000). Student Participation in a DiscussionOriented Online Course. Journal of Research on Computing in Education, 33(2), 162-177.

Schreiner, L. A., \& Nelson, D. D. (2013). The Contribution of Student Satisfaction to Persistence. Journal of College Student Retention: Research, Theory \& Practice, 15(1), 73111. https://doi.org/10.2190/CS.15.1.f

Shen, D., Cho, M.-H., Tsai, C.-L., \& Marra, R. (2013). Unpacking online learning experiences: Online learning self-efficacy and learning satisfaction. The Internet and Higher Education, 19, 10-17.

Simmering, M. J., Posey, C., \& Piccoli, G. (2009). Computer Self-Efficacy and Motivation to Learn in a SelfDirected Online Course. Decision Sciences Journal of Innovative Education, 7(1), 99-121.

Smith, P. J. (2005, February). Learning preferences and readiness for online learning. Educational Psychology, Vol.25, pp.3-12.

Roper, A. R. (2007). How students develop online learning skills. Educause Quarterly, 30(1), 62.

Saadé, R. G., He, X., \& Kira, D. (2007). Exploring dimensions to online learning. Computers in Human Behavior, 23(4), 1721-1739.

Shyu, H. Y., \& Brown, S. W. (1992). Learner control versus program control in interactive videodisc instruction: What are the effects in procedural learning. International Journal of Instructional Media, 19(2), 85-95.

Tsai, M. J., \& Tsai, C. C. (2003). Information searching strategies in web-based science learning: the role of Internet self-efficacy. Innovations in Education and Teaching International, 40(1), 43-50.

Womble, J. C. (2007). E-learning: The relationship among learner satisfaction, self-efficacy, and usefulness (Doctoral dissertation). Alliant International University, San Diego, CA.Retrieved from https://www.learntechlib.org/p/119496/ 
Wu, J. H., Tennyson, R. D., \& Hsia, T. L. (2010). A study of student satisfaction in a blended e-learning system environment. Computers \& Education, 55(1), 155-164.

Yukselturk, E., \& Yildirim, Z. (2008). Investigation of interaction, online support, course structure and flexibility as the contributing factors to students' satisfaction in an online certificate program. Journal of Educational Technology \& Society, 11(4), 51-65.

Zimmerman, B. J. (2000). Self-efficacy: An essential motive to learn. Contemporary Educational Psychology, 25, 82-91.

\begin{tabular}{|c|c|c|}
\hline \multicolumn{3}{|c|}{ Appendix - A (Survey Ins truments) } \\
\hline S.No. & Item Code & Item Description \\
\hline 1 & OLRS_CIS1 & $\begin{array}{l}\text { I feel confident in performing the basic } \\
\text { functions of Microsoft Office programs (MS } \\
\text { Word.MS Excel. and MS PowerPoint) }\end{array}$ \\
\hline 2 & OLRS_CIS2 & $\begin{array}{l}\text { I feel confident in my knowledge and skills of } \\
\text { how to manage software for online learning. }\end{array}$ \\
\hline 3 & OLRS_CIS3 & $\begin{array}{l}\text { I feel confident in using the Internet (Google, } \\
\text { Yahoo) to find or gather information for online } \\
\text { learning. }\end{array}$ \\
\hline 4 & OLRS_SDL1 & I carry out my own study plan. \\
\hline 5 & OLRS_SDL2 & $\begin{array}{l}\text { I seek assistance when facing learning } \\
\text { problems. }\end{array}$ \\
\hline 6 & OLRS_SDL3 & I manage time well. \\
\hline 7 & OLRS_SDL4 & I set up my learning goals \\
\hline 8 & OLRS_SDL5 & $\begin{array}{l}\text { I have higher expectations for my learning } \\
\text { performance. }\end{array}$ \\
\hline 9 & OLRS_LC1 & I can direct my own learning progress. \\
\hline 10 & OLRS_LC2 & $\begin{array}{l}\text { I am not distracted by other online activities } \\
\text { when learning online (instant messages, } \\
\text { Internet browsing). }\end{array}$ \\
\hline 11 & OLRS_LC3 & $\begin{array}{l}\text { I repeated the online instructional materials on } \\
\text { the basis of my needs. }\end{array}$ \\
\hline 12 & OLRS_MFL1 & I am open to new ideas. \\
\hline 13 & OLRS_MFL2 & I have motivation to learn. \\
\hline 14 & OLRS_MFL3 & I improve from my mistakes. \\
\hline 15 & OLRS_MFL4 & I like to share my ideas with others. \\
\hline 16 & OLRS_OCS1 & $\begin{array}{l}\text { I feel confident in using online tools (email, } \\
\text { discussion) to effectively communicate with } \\
\text { others. }\end{array}$ \\
\hline 17 & OLRS_OCS2 & $\begin{array}{l}\text { I feel confident in expressing my self (emotions } \\
\text { and humor) through text. }\end{array}$ \\
\hline 18 & OLRS_OCS3 & $\begin{array}{l}\text { I feel confident in posting questions in online } \\
\text { discussions. }\end{array}$ \\
\hline 19 & OL_SS1 & I was able to learn through online instructions. \\
\hline 20 & OL_SS2 & I was able to learn from the online discussions. \\
\hline 21 & OL_SS3 & $\begin{array}{l}\text { I was stimulated to do additional reading on } \\
\text { topics discussed in the online course. } \\
\end{array}$ \\
\hline 22 & OL_SS4 & I learned to value other points of view. \\
\hline 23 & OL_SS5 & $\begin{array}{l}\text { As a result of my experience with the online } \\
\text { course, I would like to participate in another } \\
\text { online course in the future. }\end{array}$ \\
\hline 24 & OL_SS6 & $\begin{array}{l}\text { The online course was a useful learning } \\
\text { experience. }\end{array}$ \\
\hline 25 & OL_SS7 & $\begin{array}{l}\text { As a result of my participation in the online } \\
\text { course, I made acquaintances with other } \\
\text { participants electronically. }\end{array}$ \\
\hline 26 & OL_SS8 & $\begin{array}{l}\text { The diversity of topics in the online course } \\
\text { prompted me to participate in the discussions. }\end{array}$ \\
\hline 27 & OL_SS9 & $\begin{array}{l}\text { I put a great deal of effort to learn the } \\
\text { technology to participate in the online course. }\end{array}$ \\
\hline
\end{tabular}

